\title{
Non-spherical Carbon Composite Agglomerates: Lab-scale Manufacture and Quality Assessment
}

\author{
Masanori NAKANO, Masaaki NAITO, Kenichi HIGUCHI and Koji MORIMOTO¹) \\ Ironmaking R\&D Div., EPC, Nippon Steel Corporation, Shintomi 20-1, Futtsu, Chiba 293-8511 Japan. \\ 1) Kimitsu R \& D Center, Tetsugen Ltd., Kimitsu 1, Kimitsu, Chiba 299-1141 Japan.
}

(Received on May 7, 2004, accepted in final form on October 5, 2004)

\begin{abstract}
For recycling steel work dust and improving blast furnace (BF) performance, a few types of non-spherical carbon-iron oxide agglomerates were manufactured in laboratory scale and their strength and reducibility were evaluated using a shatter and a tumbler tester, a simulator for lumpy zone in BF and a softening/melting tester. The flat or ragged shape was expected to enhance reducibility and to prevent the agglomerate from unwilling rolling down to the center of BF.

Agglomerate in the shape of column with concave triangle cross-section (Tetra) showed the highest yield during extruding and almost same strength compared with a commercial spherical cold-bond pellet. In reducibility Tetra excelled sinter but spherical carbon composite pellet, which denied shape effect. Reduction disintegration of Tetra initiated at $600^{\circ} \mathrm{C}$ and reached to the maximum of $60 \%$ at $860^{\circ} \mathrm{C}$, the entrance of thermal reserve zone, meaning the issue of cement bonding on disintegration remained unsolved. In case of single use, Tetra did not melt down up to the upper limit temperature of the softening/melting tester, causing S-value enlarged.

Using Tetra mixed with sinter was recommended as a trial of admixing $50 \%$ Tetra to sinter accelerate reduction rate of sinter, improving BF efficiency by $45 \mathrm{~kg} / \mathrm{t}$ decreases in RAR; moreover, the mixture remarkably reduced the pressure loss of cohesive zone.
\end{abstract}

KEY WORDS: non-spherical carbon composite agglomerate; press forming; reducibility; softening melting properties.

\section{Introduction}

Energy-efficient blast furnace $(\mathrm{BF})$ requires good reducibility of ferrous burden. The principal improving reducibility includes 1) small diameter the burden has 2) enough porosity and suitable distribution of pore diameter for maintaining gas diffusion up to elevated temperature, 3 ) close positioning of carbon to iron oxide. An agglomerate consisting of small pellets like HPS ${ }^{1)}$ satisfies the first condition; cold-bond pellet features higher reducibility mainly owing to higher porosity ${ }^{2}$; cold bonding method also realizes the third condition as a carbon-iron oxide composite pellet. ${ }^{3)}$ Such consideration leads to an ideal burden for BF: a grape-shaped carbon-iron oxide complex, despite of much difficulty to manufacture.

So many researches have been reported on spherical carbon composite pellets, ${ }^{4)}$ especially on their reduction behaviors, ${ }^{5}$ ) that we focused on their shapes and studied some shapes of non-spherical carbon-composite agglomerates (NCCAs), expecting their short gas-diffusion lengths from surface to center to enhance reducibility and their surface raggedness to improve ability of being charged at desirable positions across BF.

Cold bonding method has applied to recycling steel work dust. ${ }^{6)}$ The technology of carbon admixing and shape modi- fication would also enhance the quality of the commercial cold-bonded pellets.

As a stereotype, the shape of non-sphere weakens the strength of agglomerate. Therefore, NCCAs were manufactured in laboratory scale and evaluated in terms of strength at first. Consequently, the strongest NCCA was investigated in terms of reducibility using blast furnace simulator (BIS: simulator of lumpy zone in BF) and softening/melting tester (SMUL) in comparison with a spherical cementbonded carbon-composite pellet.

\section{Manufacturing NCCAs}

\subsection{Procedure of Manufacturing NCCAs}

Raw material for NCCAs was the raw mixture for Kimitsu cement-less cold-bond pellet (CCP) plant, ${ }^{7)}$ consisting of $30 \% \mathrm{BF}$ dust, $40 \% \mathrm{BOF}$ dust and $6 \%$ inorganic binder, having the chemical composition in Table 1. Utilizing the plant's raw mixture facilitated preparation of experimental one in large amount needed for strength measurements and it enable direct comparison of the strengths of NCCAs with that of CCP already in commercial use as a ferrous burden for BF.

Figure 1 shows three types of NCCAs manufactured in the present study: agglomerate shaped like grape (Grape), 
Table 1. Chemical compositions of agglomerates. (mass $\%$ )

\begin{tabular}{|c|c|c|c|c|c|c|c|c|}
\hline & T.Fe & $\mathrm{FeO}$ & $\mathrm{CaO}$ & $\mathrm{SiO}_{2}$ & $\mathrm{Al}_{2} \mathrm{O}_{3}$ & $\mathrm{MgO}$ & $\mathrm{C} / \mathrm{S}$ & T.C \\
\hline \multicolumn{9}{|c|}{$<$ For manufacturing test $>$} \\
\hline $\begin{array}{r}\text { Tetra, Flake, CCP } \\
<\text { < For quality evaluat }\end{array}$ & $\begin{array}{l}51.7 \\
\text { test> }\end{array}$ & - & 3.67 & 2.6 & 0.8 & - & 1.4 & 17.0 \\
\hline Tetra, SP & 46.3 & 0 & 10.1 & 4.4 & 1.1 & 0 & 2.3 & 15.4 \\
\hline Sinter & 57.8 & 7.0 & 10.1 & 4.9 & 1.9 & 0.6 & 2.1 & - \\
\hline
\end{tabular}

Table 2. Comparison of NCCAs with CCP and sinter in yield and strengths. (mass\%)

\begin{tabular}{cccccc}
\hline Shape & $\begin{array}{c}\text { Binder } \\
(\text { mass\%) }\end{array}$ & $\begin{array}{c}\text { Moisture } \\
(\text { mass\%) }\end{array}$ & $\begin{array}{c}\text { Yield } \\
(\text { mass\%) }\end{array}$ & $\begin{array}{c}\text { Shatter } \\
(-5 m m \text { mass\%) }\end{array}$ & $\begin{array}{c}\text { Tumbler } \\
(-3 m m \text { mass\%) }\end{array}$ \\
\hline Grape & 10 & 10 & 70 & 6.9 & 7.4 \\
Flake & 6 & 12 & 68 & 8.4 & 6.9 \\
Tetra & 6 & 12 & 84 & 7.3 & 8.0 \\
\hline CCP & 6 & 10 & - & 5.4 & 7.1 \\
\hline
\end{tabular}

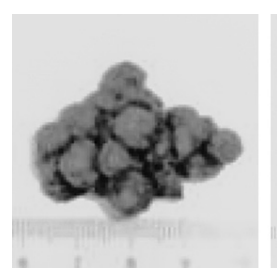

(a) Grape

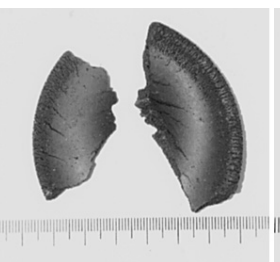

(b) Flake

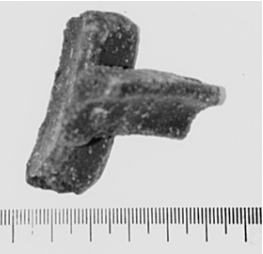

(c) Tetra
Fig. 1. Appearance of NCCAs.

curved flake (Flake) and column of concave triangle crosssection (Tetra).

Grape was manufactured as follows: Sieved out of green pellets flowing in a Kimitsu CCP plant line, 5-8 mm pellets were coated with cement slurry before piled $200 \mathrm{~mm}$ high in a container. Cured for two weeks under a $1 \mathrm{kPa}$ load, the solidified slab was arbitrarily broken into pieces. Total binder content summed up to $10 \%, 4 \%$ more than those of Tetra and Flake for inter-pellets bonding.

Extruding method was applied for manufacturing Tetra and Flake. Extruder, FM-50E made by Miyazaki-tekko Ltd., typed a one-cylinder screw-driven machine of the specification in Fig. 2.

Since moisture of raw mixture affects performance of extruder and quality of product, preliminary tests were conducted to determine the optimum moisture. At 9\% moisture, friction of raw mixture against casing increased motor load and cracks appeared on the surface of output. At $13 \%$ moisture, the load decreased to the freeload state but the output became sticky and too soft to maintain the desirable shape. Figure 3 summarized such findings, suggesting that $10-12 \%$ is optimum moisture for extruding of the present materials.

After kneading raw materials together with $12 \%$ water for five minutes in a ball mill, the mixture was molded into Tetra or Flake by changing dies. The output was handsieved by $5 \mathrm{~mm}$ and yield was calculated as percentage of the oversize. The product, the oversize of the output, was cured for two weeks in a room prior to strength measurements.

\subsection{Comparison of NCCAs and CCP in Yield and Strength}

Strengths were measured by shatter test and tumbler test. Shatter strength was defined as $-5 \mathrm{~mm}$ percentage after dropping 4 times from $2 \mathrm{~m}$ high onto a steel plate. Tumbler

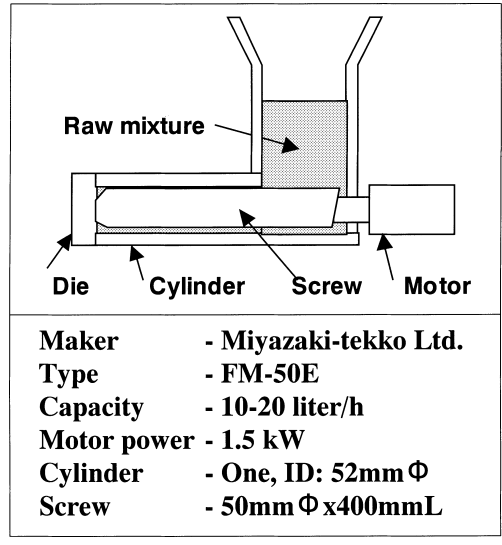

Fig. 2. Specifications of extruder.

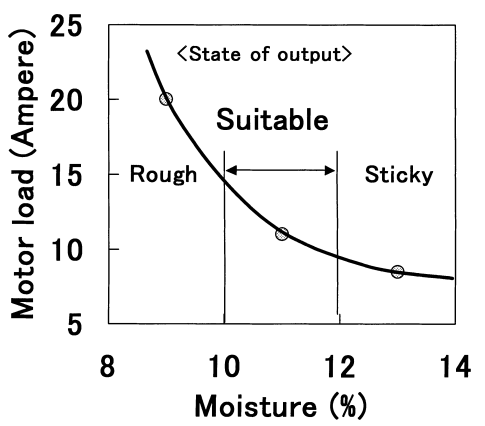

Fig. 3. Change of extruding performance with moisture content of raw mixture.

strength was $-3 \mathrm{~mm}$ percentage after 500 rotations in the same drum used for RDI measurement (JIS M8720 (2001)).

Table 2 shows results for NCCAs in terms of yield and strengths. Grape and Flake were inferior to others in yield, meaning they cost more for production. Tetra was slightly behind CCP in strengths owing to its angular cross-section and $2 \%$ more water requirement for stable extruding operation. The differences, however, were acceptably small enough that the tetra proceeded to reducibility tests as described in the next section.

\section{Reduction and Melting Behavior of Tetra-type NCCA}

\subsection{Experimental Apparatus and Conditions}

Since reduction tests refused deviation among samples, commercial hematite for magnetic tape was used in place of 
iron dusts. The Tetra here consisted of $66 \%$ of the hematite, $19 \%$ powdery coke (CDQ dust) and $15 \%$ cement, having the chemical composition in Table 1.

Reduction behavior of burden in lumpy zone dominates the reaction efficiency of BF. It was simulated using a BF inner reaction simulator (BIS). The $\mathrm{BIS}^{8)}$ is a simulator originated from BORIS furnace, ${ }^{9)}$ but modified to work under an adiabatic condition, which provides the burden a real reducing atmosphere, i.e. a posteriori variation of the furnace temperature that the nature of burden and heat transfer determine. Supplied with experimental gas equivalent to $1363 \mathrm{Nm}^{3} / \mathrm{t}$ Bosch gas composing of $35.6 \% \mathrm{CO}$, $4.4 \% \mathrm{H}_{2}$ and $60.0 \% \mathrm{~N}_{2}$, BIS ran under the total carbon consumption set at $480 \mathrm{~kg} / \mathrm{t}$ in reducing agent ratio (RAR).

Softening and melting behavior around cohesive zone is another important property for ferrous burden. It was evaluated using an under-load softening/melting tester (SMUL). ${ }^{10)}$ The experimental condition is shown in Table 3.

As a reference, commercial sinter sized within 10-15 $\mathrm{mm}$ and spherical pellet (SP) of the same size underwent SMUL test as well, where the SP was prepared using a disc pelletizer of $1 \mathrm{~m}$ in diameter from the same raw mixture.

Table 4 shows burden conditions of BIS and SMUL tests with objective of each run. Chronologically, SMUL tests for sinter, Tetra and SP of single use (S1-S3) preceded to compare their reducibility and to evaluate shape effect thereon; another test for Tetra-sinter mixture (S4) followed as $\mathrm{S} 2$ test revealed Tetra's disadvantage in a melting property in case of single use. The mixture showed so good behavior in the SMUL test that BIS tests on the mixture proceeded to quantify the mixture's effect on reducing agent ratio (RAR). Microscopic observation and chemical analysis on samples taken out from various locations different in temperature also provided some information on

Table 3. Softening/melting test condition.

\begin{tabular}{|c|c|}
\hline \multicolumn{2}{|l|}{ Sample } \\
\hline Size & $10-15 \mathrm{~mm}$ \\
\hline Coke Size & $10-15 \mathrm{~mm}$ \\
\hline Initial layer & 70mm H \\
\hline Crucible & $\begin{array}{l}\text { Graphite, } \\
85 \mathrm{~mm} \text { (ID) }\end{array}$ \\
\hline \multicolumn{2}{|l|}{ Reduction } \\
\hline \begin{tabular}{|l|l} 
Gas \\
composition
\end{tabular} & $\begin{array}{l}\mathrm{CO}: 29.4 \text { vol\% } \\
\mathrm{H}_{2}: 3.6 \text { vol\% } \\
\mathrm{N}_{2}: 67 \text { vol\% }\end{array}$ \\
\hline Flow rate & $34 \mathrm{NI} / \mathrm{min}$ \\
\hline Heating & $\begin{array}{l}10^{\circ} \mathrm{C} / \mathrm{min} \\
\left(800-1000^{\circ} \mathrm{C}\right) \\
5^{\circ} \mathrm{C} / \mathrm{min} \\
\left(1000-1600^{\circ} \mathrm{C}\right)\end{array}$ \\
\hline Load & $98 \mathrm{kPa}$ \\
\hline
\end{tabular}

reduction behavior of Tetra, which helped to interpret some results of SMUL tests.

Results below are arranged in the order of technical meaning for easy comprehension.

\subsection{Reduction Behavior of Tetra}

\subsubsection{Sample Observation after Reduction of Tetra}

Figure 4 shows reduction behavior of Tetra from top to cohesive zone of BF as a result of optical microscopic observation of samples after BIS test of $50 \%$ Tetra- $50 \%$ sinter. Before experiment (No. 0), mere coke particles were visible in ultra fine matrix of hematite and cement. At $620^{\circ} \mathrm{C}$ (No. 5), red color inherent to powdery hematite in the matrix had disappeared, suggesting the hematite has reduced to magnetite. At $860^{\circ} \mathrm{C}$ (No. 7) metal particles had appeared homogeneously. At $1200^{\circ} \mathrm{C}$ (No. 12) the metal particles still remained spherical with $0.02-0.05 \mathrm{~mm}$ in diameter; relict coke and slag particles seemed to prevent them from union. At any stage reduction proceeded homogeneously; no reaction zone appeared.

\subsubsection{Effect of Shape on Reduction Degree}

Since SMUL test runs under closer condition to BF than the popular method of JIS-RI (JIS-M8713 (1993)), the SMUL test is preferable to evaluate reducibility of agglomerate.

Figure 5 shows change in reduction degree of Tetra, SP and sinter with temperature in SMUL tests numbered S1-S3. Tetra showed better reducibility than sinter, but unexpectedly did not exceed SP. This fact implied that reducibility was independent on shape as far as carbon composite agglomerate.

The ISIJ's review ${ }^{11)}$ summarized that solution loss reaction of carbon determines the reduction rate of carbon composite pellet and that close contact of carbon and iron oxide need not diffusion of gases contributing to the reaction. This situation could be the reason for the independency of reducibility on shape. Even if the reduction from wustite to iron was rate-determining reaction, the close contact caused the ubiquitous iron formation as observed in Fig. 4, leading to the same conclusion.

\subsection{Reduction Disintegration of Tetra}

BIS test can provide burden an index concerning the disintegration in BF shaft zone. In the present study it was measured by tumbling the sample taken out of the furnace after reduction by the method of RDI measurement (JISM8720 (2 001)).

Table 4. Burden conditions for SMUL and BIS tests. (mass \%)

\begin{tabular}{|c|c|c|c|c|}
\hline & Sinter & Tetra & SP & Objective \\
\hline$<$ Softening/melting > & & & & \\
\hline S1: Sinter (Base) & 100 & 0 & 0 & \\
\hline S2: Tetra & 0 & 100 & 0 & Comparison of Tetra with sinter and SP in \\
\hline S3: SP & 0 & 0 & 100 & Reduction degree and shape effect \\
\hline $\begin{array}{l}\text { S4: Tetra-sinter mixture } \\
<\text { BIS }>\end{array}$ & 50 & 50 & 0 & 2) Softening/melting behavior \\
\hline $\begin{array}{l}\text { B1: Sinter (Base) } \\
\quad(\text { RAR=480kg/t) }\end{array}$ & 100 & 0 & 0 & \\
\hline $\begin{array}{l}\text { B2: Tetra-sinter mixture } \\
(\mathrm{RAR}=480 \mathrm{~kg} / \mathrm{t})\end{array}$ & 50 & 50 & 0 & $\begin{array}{l}\text { 1) Microscopy of Tetra during reduction } \\
\text { 2) RDI of Tetra compared with sinter } \\
\text { 3) Effect of mixing Tetra on RAR }\end{array}$ \\
\hline $\begin{array}{l}\text { B3: Tetra-sinter mixture } \\
(\mathrm{RAR}=450 \mathrm{~kg} / \mathrm{t})\end{array}$ & 50 & 50 & 0 & Confirmation of RAR reduction \\
\hline
\end{tabular}



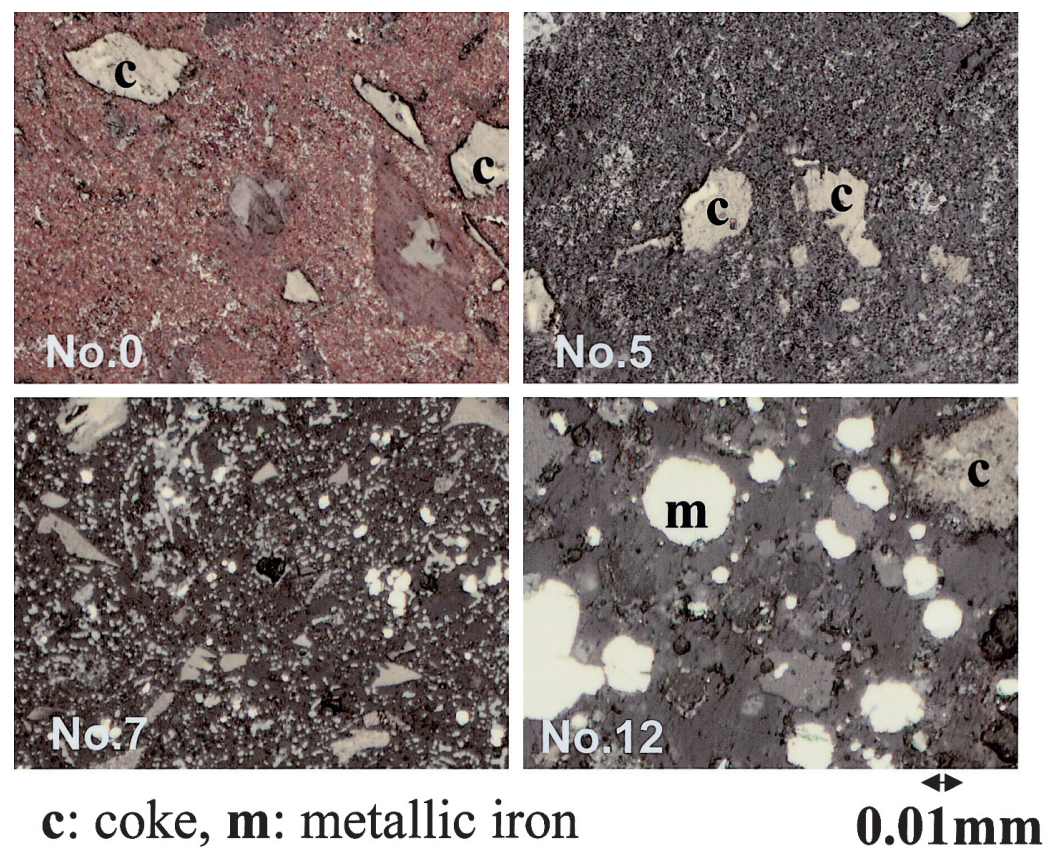

Fig. 4. Microscopic observation of Tetra samples after BIS test in condition of $50 \%$ Tetra- $50 \%$ sinter. (No. 0) As extruded, (No. 5) At $620^{\circ} \mathrm{C}$, (No. 7) At $860^{\circ} \mathrm{C}$ and (No. 12) at $1200^{\circ} \mathrm{C}$.

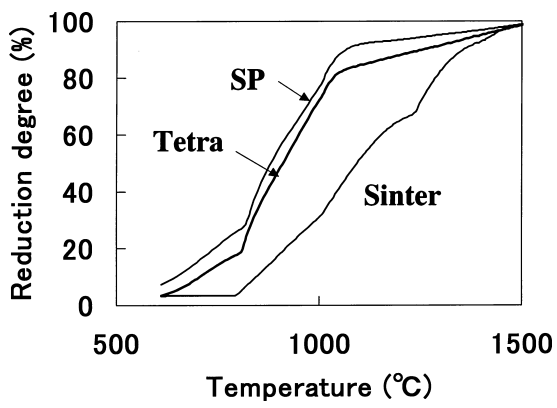

Fig. 5. Change of reduction degrees with temperature in SMUL tests (S1-S3).

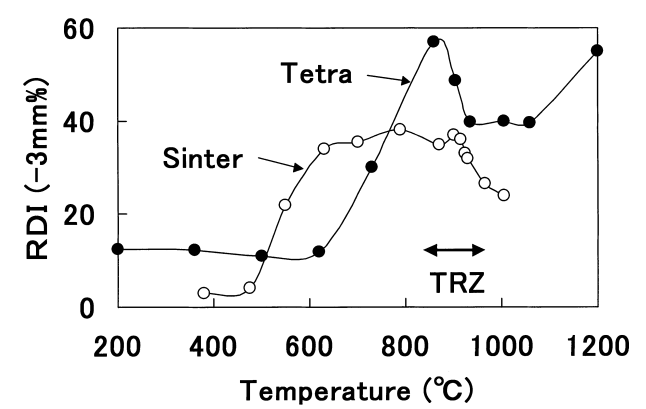

Fig. 6. Disintegration of Tetra and sinter after reduction in case of $50 \%$ Tetra- $50 \%$ sinter BIS test (B2).

Figure 6 shows $-3 \mathrm{~mm} \%$ after tumbling (RDI) of Tetra and sinter from 50\% Tetra-50\% sinter BIS test (B2). Initiating around $600^{\circ} \mathrm{C}$, Tetra's disintegration attained to the maximum of $60 \%$ at $860^{\circ} \mathrm{C}$, because cement bonding loses its strength during dehydration; then the index recovered to $40 \%$ in thermal reserve zone (TRZ: the location was decided based on temperature profile in Fig. 9) probably because of metal formation; from 1100 to $1200^{\circ} \mathrm{C}$ it increased again probably because metal formation terminated despite carbon gasification continued. In contrast, sinter started to disintegrate from $500^{\circ} \mathrm{C}$ and attained to minimum

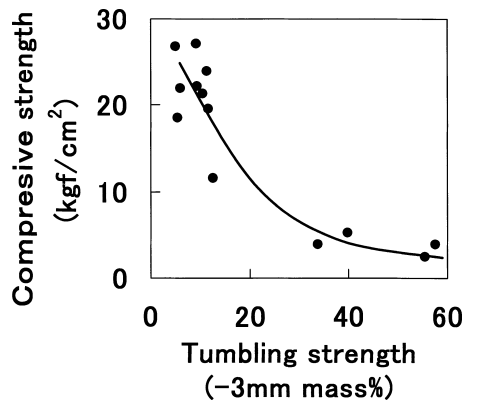

Fig. 7. Relationship between tumbling strength and compressive strength in case of non-carbon cement-bond pellet after BIS test.

strength around $600^{\circ} \mathrm{C}$; the strength recovered from the half way of TRZ from $900^{\circ} \mathrm{C}$; such behavior of sinter coincided with old information. The comparison between them concluded Tetra was inferior to sinter in the index.

Takahashi et al. ${ }^{2)}$ reported that compressive strength of char-contained cement-bonded pellet decreases from 100 to $20 \mathrm{kgf} / \mathrm{p}\left(=11 \mathrm{kgf} / \mathrm{cm}^{2}\right)$ in a shaft furnace, but without causing significant influence on the operation, adding that fired pellet also lose its strength from 200 to $30-50 \mathrm{kgf} / \mathrm{p}$. Estimated on a base of relationship between RDI and compressive strength obtained in case of cement-bond pellet as shown in Fig. 7, $60 \%$ in RDI corresponded to $5 \mathrm{~kg} / \mathrm{cm}^{2}$ in the compressive strength. The value for the minimum strength of Tetra was half behind that of Takahashi's pellet in terms of compressive strength.

The results and discussions so far on disintegration failed to prove that Tetra causes no problem on BF operation.

\subsection{Softening/Melting Behavior of Tetra}

Table 5 shows softening/melting properties of Tetra. Temperature to initiate softening (Ts), defined as the temperature at which pressure loss across the bed increased up to $2.0 \mathrm{kPa}$, was lower than that of sinter. Temperature to 
initiate metal dripping (Td), defined as the temperature at which melt receiver detects the first drip, ranged over; in another index, ratio of metal dripped (Rmd), calculated from total weight of dripped metal during the run, remained zero. The observation of sample heated up to $1200^{\circ} \mathrm{C}$ in BIS (Fig. 4, No. 12) provided an intuitive interpretation of the phenomena: relict coke or much slag suspended metal droplet inside the Tetra over melting point of pig iron.

SP and iron-ore hot briquette bonded with metallurgical coal $^{12)}$ also exhibited zero Rmd. Since common characteristic among Tetra and them was carbon bearing, the cause for Tetra's zero Rmd was induced to be the carbon addition rather than slag composition.

Sato et $a l .{ }^{13)}$ required basicity $(\mathrm{C} / \mathrm{S})$ more than 1.2 and slag volume (SV) more than $220 \mathrm{~kg} / \mathrm{t}-\mathrm{Fe}$ for cement-bond pellet (not carbon composite) to win a lower-than-sinter pressure loss. Their request based on the fact that whisker formation caused the pellet swelling and consequent disintegration increasing pressure loss. Tetra, however, formed no whisker during reduction, probably because composite carbon prompted ubiquitous formation of iron embryos. The factor ruling pressure loss must differ depending on whether carbon exists in the agglomerate or not.

\section{Effective Usage of Non-spherical Carbon Composite Agglomerate}

Cold bond process is so economical and eco-friendly that some integrated steel works apply it for dust recycling. ${ }^{5)}$ Still they restrict cold-bond pellet dose for BF because dehydration reduces its strength as described in Sec. 3.3. In such situation, single use of NCCA as ferrous burden sounds unrealistic. Otherwise, mixing Tetra with sinter was tried to improve softening/melting properties and RAR in BF operation. The composition of the mixture was $50 \%$ Tetra-50\%sinter.

\subsection{Results of Softening/Melting Test for Tetra-Sinter Mixture}

SMUL tests proved that the mixture improved the high-

Table 5. High temperature properties of Tetra in comparison with SP and sinter.

\begin{tabular}{lccc}
\hline & $\begin{array}{c}\text { Sinter } \\
\text { (S1) }\end{array}$ & $\begin{array}{c}\text { Tetra } \\
\text { (S2) }\end{array}$ & $\begin{array}{c}\text { SP } \\
\text { (S3) }\end{array}$ \\
\hline Reduction degree at $1000^{\circ} \mathrm{C}(\%)$ & 31.3 & 76.4 & 78.1 \\
Reduction degree at $1200^{\circ} \mathrm{C}(\%)$ & 65.2 & 98.0 & 93.5 \\
Temperature of softening $\left({ }^{\circ} \mathrm{C}\right)$ & 1222 & 1129 & 1007 \\
Temperature of dripping $\left({ }^{\circ} \mathrm{C}\right)$ & 1462 & $>1542$ & $>1550$ \\
S value $\left(\mathrm{kPa}^{\star}\right.$ min) & 1090 & 3305 & 1540 \\
Metal dripped $(\%)$ & 56.4 & 0 & 0 \\
\hline
\end{tabular}

temperature properties [Fig. 8]: Reducibility enhanced proportionally with increasing the ratio of Tetra. The difference between $\mathrm{Ts}$ and $\mathrm{Td}$ showed minimum at $50 \%$ mixing of Tetra, meaning the mixture minimized the thickness of cohesive zone in BF. It also reflected the drastic decrease in $\mathrm{S}$ value at the mixing composition. Supposedly, carbon in Tetra concurrently affected on the melting process of sinter, yielding such effects.

\subsection{Results of BIS Test for Tetra-Sinter Mixture}

Figure 9 shows BIS results: changes of temperature and reduction degree on axis of dimensionless distance from furnace top to bottom. The reduction degree here was calculated by oxygen balance based on gas analysis.

Comparison of temperature profiles between the mixture (B2) and sinter single (B1) set under the condition of $480 \mathrm{~kg} / \mathrm{t}$ in RAR showed that Tetra addition lowered temperature of $\mathrm{TRZ}$ from 1050 to $820^{\circ} \mathrm{C}$; and reduction degree curves showed the mixture was reduced faster than sinter single, especially after passing TRZ, improving $\mathrm{CO}_{2} /\left(\mathrm{CO}+\mathrm{CO}_{2}\right)$ (=Y-co) of off-gas from 45.5 to $54.0 \%$.

Table 6 shows pairs of the shaft efficiency (E-shaft) and true RAR estimated based on observed Y-co of off-gas and observed temperature of TRZ (TR) using heat-and-mass balance calculations. ${ }^{14)}$ The mixture improved the E-shaft by $1.5 \%$; the effect on E-shaft combined with that on lowering of TRZ temperature accounted for $35-\mathrm{kg} / \mathrm{t}$ reductions in true RAR.

An additional run for the mixture (B3) was conducted under $450 \mathrm{~kg} / \mathrm{t}$ RAR to verify the validity of the above estimation. Temperature profiles for Tetra-sinter mixtures

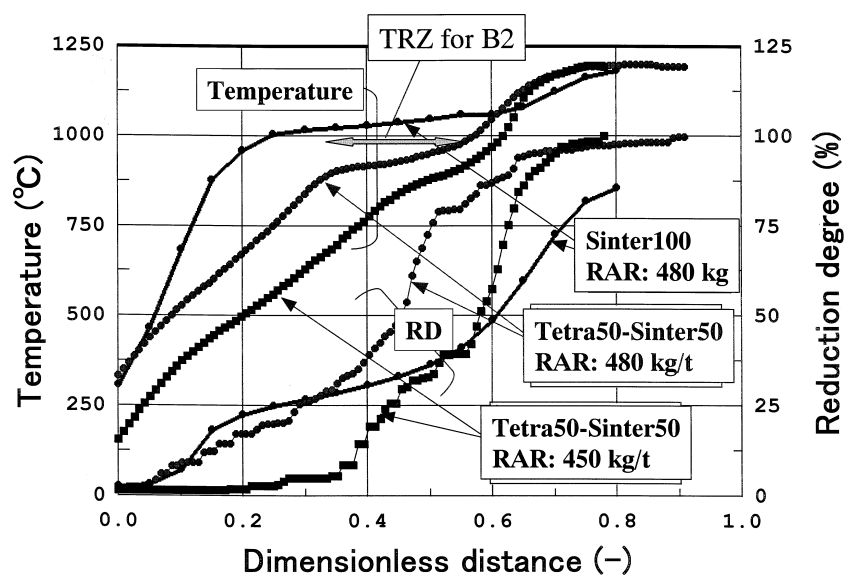

Fig. 9. Temperature and reduction degree profiles (B1-B3) on axis of dimensionless distance from furnace top to bottom maintained at $1200^{\circ} \mathrm{C}$.
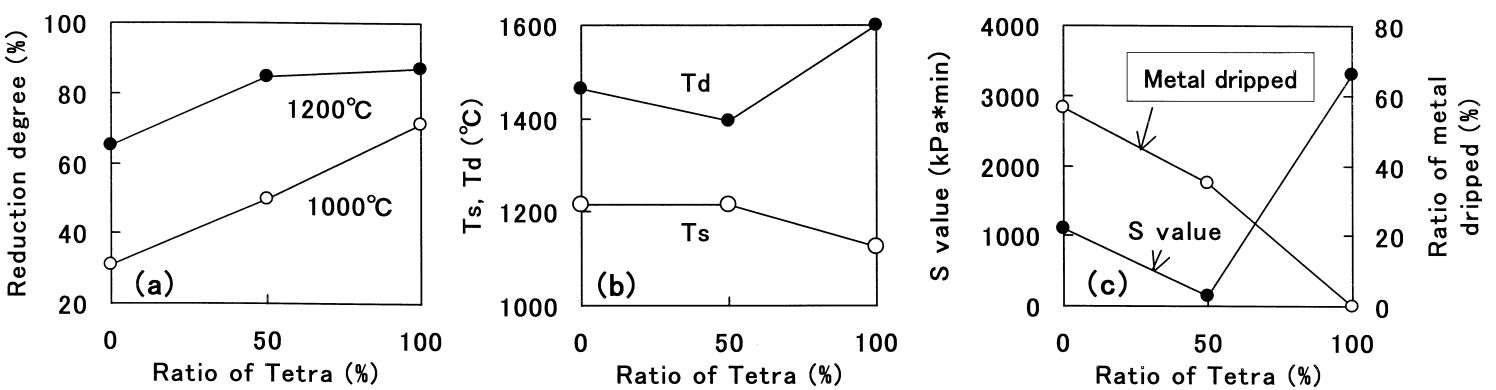

Fig. 8. Change in high temperature properties of sinter by $50 \%$ mixing of Tetra (S4). 
Table 6. Estimation of RAR based on heat-and-mass balance model.

\begin{tabular}{lccccc}
\hline & $\begin{array}{c}\text { Y-co } \\
(\text { vol\%) }\end{array}$ & $\begin{array}{c}\text { TR } \\
\left({ }^{\circ} \mathrm{C}\right)\end{array}$ & $\begin{array}{c}\text { E-shaft } \\
(\%)\end{array}$ & $\begin{array}{c}\text { True } \\
\text { RAR } \\
(\mathrm{kg} / \mathrm{t})\end{array}$ & \\
\hline B1: Sinter100\%-480kg/t & 45.5 & 1050 & 93.5 & 432 & \\
B2: Tetra 50\%-480kg/t & 54.0 & 880 & 95.0 & 397 & -35 \\
B3: Tetra 50\%-450kg/t & 57.2 & 880 & 96.4 & 387 & -45 \\
\hline Y-co: Gas utilization ratio of off-gas, & & & \\
TR: Temperature of thermal reserve zone, & & \\
E-shaft: Shaft efficiency, \\
True RAR: Reducing agent ratio estimated based on the model.
\end{tabular}

Table 7. Sample number, temperature at inner tube the sample located and chemical analysis of Tetra and sinter for the BIS test of Tetra-sinter mixture (B2).

\begin{tabular}{|c|c|c|c|c|c|c|c|c|}
\hline \multirow[b]{2}{*}{$\begin{array}{c}\text { Sample } \\
\text { No. }\end{array}$} & \multirow[b]{2}{*}{$\begin{array}{c}\text { Temperature } \\
\text { of inner tube } \\
\left({ }^{\circ} \mathrm{C}\right)\end{array}$} & \multicolumn{3}{|c|}{ Sinter } & \multicolumn{4}{|c|}{ Tetra } \\
\hline & & $\begin{array}{c}\mathrm{T} . \mathrm{Fe} \\
\text { (mass } \\
\% \text { ) }\end{array}$ & $\begin{array}{c}\text { M.Fe } \\
\text { (mass } \\
\% \text { ) }\end{array}$ & $\begin{array}{c}\mathrm{FeO} \\
\text { (mass } \\
\% \text { ) }\end{array}$ & $\begin{array}{c}\text { T.Fe } \\
\text { (mass } \\
\% \text { ) }\end{array}$ & $\begin{array}{c}\text { M.Fe } \\
\text { (mass } \\
\% \text { ) }\end{array}$ & $\begin{array}{c}\mathrm{FeO} \\
\text { (mass } \\
\% \text { ) }\end{array}$ & $\begin{array}{c}\mathrm{FC} \\
\text { (mass } \\
\% \text { ) }\end{array}$ \\
\hline riginal & & 57.35 & 0.20 & 6.32 & 44.42 & 0.34 & 0.24 & 15.8 \\
\hline 3 & & 57.8 & 0.22 & 6.47 & 43.88 & 0.22 & 3.02 & 15 \\
\hline 5 & & 57.36 & 0.22 & 9.49 & 45.91 & 0.58 & 19.73 & 15.7 \\
\hline 7 & 86 & 60.64 & 0.58 & 50.38 & 50.12 & 3.66 & 49.18 & 16.5 \\
\hline 9 & & 62.95 & 8.02 & 60.47 & 56.14 & 31.79 & 25.77 & 15.0 \\
\hline 11 & & 72.04 & 52.70 & 20.58 & 62.53 & 59.80 & 0.66 & 12.4 \\
\hline 12 & 120 & 74.23 & 71.08 & 2.23 & 64.26 & 62.25 & 0.82 & 11.2 \\
\hline
\end{tabular}

under $450 \mathrm{~kg} / \mathrm{t}$ and sinter single under $480 \mathrm{~kg} / \mathrm{t}$ in Fig. 9 showed that the $30-\mathrm{kg} / \mathrm{t}$ slashes in RAR delayed the position of TRZ entrance downward and decreased the time for heating the burden up to $1200^{\circ} \mathrm{C}$; however, Y-co of off-gas of the mixture under $450 \mathrm{~kg} / \mathrm{t}$ (B3) increased $3.2 \%$ more than that under $480 \mathrm{~kg} / \mathrm{t}$ (B2) and reduction degree curves showed the index of the mixture under $450 \mathrm{~kg} / \mathrm{t}$ (B3) overcame that of sinter single (B1) at the position of furnace bottom. The surplus meant possibility of more RAR reduction than $30 \mathrm{~kg} / \mathrm{t}$. Estimated true RAR for the run (B3) accounted for $387 \mathrm{~kg} / \mathrm{t}, 45-\mathrm{kg} / \mathrm{t}$ slashes from $432 \mathrm{~kg} / \mathrm{t}$ for the base condition (B1) [Table 6].

\subsection{Discussion on the Mechanism for Tetra to Accel- erate Reduction Rate of the Mixture}

Chemical analysis of samples after BIS test [Table 7] can tell the change of reduction degree of Tetra and sinter separately with temperature. Figure $\mathbf{1 0}$ shows the result in terms of oxygen/iron ratio (OR).

At $860^{\circ} \mathrm{C}$ (No. 7) Tetra's OR decreased to 1.0 , meaning Tetra completed transformation from hematite to wustite, which microscopic observation confirmed; major reductant for the reaction was ambient $\mathrm{CO}$ gas because Tetra scarcely lost its carbon content; under such condition, faster reduction rate of Tetra than sinter up to $860^{\circ} \mathrm{C}$ seemed due to Tetra's larger porosity than sinter's. ${ }^{2)}$ From $860^{\circ} \mathrm{C}$ gasification of composite carbon activated; per unit mol $\mathrm{Fe}$, $0.87 \mathrm{~mol}$ carbon gasified between $860^{\circ} \mathrm{C}$ and $1060^{\circ} \mathrm{C}$ corresponded to $0.95 \mathrm{~mol}$ oxygen removal, which suggested that direct reduction contributed to most of wustite-to-iron reduction inside Tetra. By such mechanisms Tetra excelled sinter in reduction rate.

Even the sinter, when mixed with Tetra, showed noteworthy advance in reduction compared with sinter of single use; as a fact, sinter with Tetra finished to-magnetite reduction before $860^{\circ} \mathrm{C}$ otherwise sinter single remained almost unreduced until the temperature. Obviously solution loss reaction of composite carbon, activated over $860^{\circ} \mathrm{C}$, was

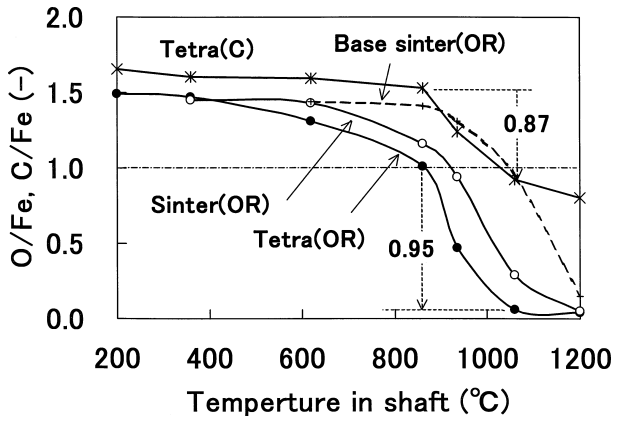

Fig. 10. Comparison of reduction degrees among sinters and Tetra on axis of temperature.

more vigorous than that of normally layered coke because of finer particle size and closer contact to iron oxide; such situation enriched $\mathrm{CO}$ concentration of descending gas, accelerating sinter reduction as well as Tetra within the region from 600 to $860^{\circ} \mathrm{C}$. The $\mathrm{CO}$ rich atmosphere probably continued over $860^{\circ} \mathrm{C}$ and accelerated sinter reduction there.

As described above, composite carbon in Tetra produced two effects: accelerating reduction not only of Tetra itself, but also of neighboring sinter. The self-reducing effect is well known, especially in case of single sphere; the effect derives from the mechanism that close positioning of iron oxide and carbonaceous material activates solution loss reaction of the carbon. The present research did not advance the understanding on the mechanism but verified the self-reducing effect of admixing carbon under a closer reduction condition to $\mathrm{BF}$ using BIS. The neighbor-reducing effect caused by $\mathrm{CO}$ richer atmosphere the composite carbon produced was also confirmed in the BIS condition; the effect would act as another incentive to use carbon composite agglomerates.

Energy efficiency of BF, Y-co of off-gas, reflects Y-co at TRZ that wustite-iron equilibrium dominates. To decrease RAR, Naito et al. ${ }^{7}$ focused on two factors controlling the Y-co at TRZ: E-shaft and temperature there, and proved that sinter of good reducibility improve the E-shaft; high reactivity coke lower the TRZ temperature. In contrast Tetra improved both at the same time: TRZ temperature lowering by $170^{\circ} \mathrm{C}$, E-shaft increasing by $2.9 \%$.

The improvement in reducibility mostly derived from fine coke size contained in Tetra and its close contact to sinter. This implies nut coke charged in sinter layer can behave in the same manner as Tetra and some composition of sinter, carbon composite agglomerate and nut coke involves the ideal burden. Searching the composition is further problem.

\section{Conclusions}

Non-spherical carbon composite agglomerates: Grape, Flake and Tetra were manufactured in laboratory scale and their qualities were evaluated mainly using a softening/ melting tester (SMUL) and a blast furnace inner simulator (BIS).

(1) Tetra produced by extruding showed the best performance in processing and almost same strength as a commercial spherical cold-bond pellet. 
(2) Tetra showed better reducibility than sinter though its shape effect was not recognized in comparison with spherical carbon composite pellet. The strength of the agglomerate in the BIS reduced to $5 \mathrm{~kg} / \mathrm{cm}^{2}$ at the entrance of TRZ, meaning the issue of cement bonding on disintegration remained unsolved. In case of single use of Tetra, the absence of melting down was observed up to the upper limit temperature of MSUL, causing S-value enlarged.

(3) Mixing 50\% Tetra to sinter accelerate reduction rate of sinter, improving BF efficiency by $45 \mathrm{~kg} / \mathrm{t}$ decreases in RAR reflecting $170^{\circ} \mathrm{C}$ lowering of TR and $2.9 \%$ increasing of E-shaft. Moreover, the mixture remarkably reduced the pressure loss of cohesive zone, meaning another potential to stabilize BF operations.

\section{Acknowledgements}

We appreciate Ministry of Education, Culture, Sports, Science and Technology, Japanese Government for funding the present research undertaken as a part of the project on 'Science and Technology of Innovative Ironmaking for Aiming at Energy Half Consumption'.

\section{REFFERENCES}

1) N. Sakamoto, H. Noda, Y. Iwata, H. Saito and T. Miyashita: Tetsu-toHagané, 73 (1987), 1504

2) T. Inazumi: Research Projects of Ironmaking Technology, ISIJ, Tokyo, (1993), 67.

3) A. Takahashi and R. Takahashi: Tetsu-to-Hagané, 70 (1984), 37.

4) M. C. Mantovani and C. Takano: Proc. of 2nd ICSTI, ISS, Warrendale, PA, (1998), 1255.

5) Y. Iguchi and F. Meng: Proc. of 3rd ICSTI, VDEh, Düsseldorf, (2003), 413

6) T. Inazumi, H. Furutaku, T. Kuwabara and K. Esaki: Conservation \& Recycling, 6 (1983), 167.

7) S. Amano, H. Abe, I. Yamaguchi, H. Matsuoka, M. Takano, M. Aida and K. Morita: Tetsu-to-Hagané, 75 (1989), 767.

8) M. Naito, A. Okamoto, K. Yamaguchi, T. Yamaguchi and Y. Inoue: Tetsu-to-Hagané, 87 (2001), 357.

9) B. Bonnivard and A. Rist: Rev. Metall. Cah. Inf. Tech., 59 (1962), 401.

10) Y. Hosotani, N. Konno, K. Yamaguchi, T. Orimoto and T. Inazumi: ISIJ Int., 36 (1996), 1439.

11) Reduction Reaction Research Group, ISIJ: Private communication, (2000)

12) M. Shimizu, T. Maeda, A. Kasai and Y. Matsui: Proc. of 3rd ICSTI, VDEh, Düsseldorf, (2003), 408.

13) K. Sato, Y. Sawamura, K. Kanbara and T. Furui: Tetsu-to-Hagané, 65 (1979), 1673.

14) K. Yamaguchi, H. Ueno, M. Naito and K. Tamura: Tetsu-to-Hagané, 77 (1991), 1609. 